\title{
雷诺数对藻类垂向分布特性的影响"
}

\author{
安 强, 龙天渝 ${ }^{* *}$, 刘春静, 雷 雨, 李 哲 \\ （重庆大学三峡库区生态环境教育部重点实验室,重庆 400045)
}

\begin{abstract}
摘 要: 为研究紊流水体中藻类的垂向分布特性,依据三峡水库次级河流回水段的水动力状况,自行设计了水流实验装 置, 选取次级河流回水区水华高发时段的气候状况和营养盐水平为实验条件,研究了雷诺数对蓝藻、绿藻和硅藻垂向分 布的影响以及雷诺数对不同水深处藻类的悬浮和聚集行为的作用. 研究结果表明:在水温为 $20^{\circ} \mathrm{C}$ 、光照强度为 $5000 \mathrm{~lx}$ 的富 营养水体中, 当断面平均流速在 $0 \sim 0.005 \mathrm{~m} / \mathrm{s}$ 、雷诺数在 $0 \sim 1750$ 时, 蓝藻主要悬浮聚集在 $0.2 \sim 0.8 \mathrm{~m}$ 的表层水体中; 而 当断面平均流速在 $0.1 \sim 0.5 \mathrm{~m} / \mathrm{s}$ 、雷诺数在 $35000 \sim 175000$ 时, 硅藻主要悬浮聚集在 $0.2 \sim 0.8 \mathrm{~m}$ 的表层水体中; 与蓝藻 和硅藻相比, 绿藻适宜的雷诺数范围更宽, 当断面平均流速在 $0 \sim 0.05 \mathrm{~m} / \mathrm{s}$ 、雷诺数在 $0 \sim 17500$ 时, 绝大部分的绿藻都能 悬浮聚集在 $0.2 \sim 0.8 \mathrm{~m}$ 的表层水体中.
\end{abstract}

关键词: 雷诺数;紊流; 藻类;垂向分布;三峡水库

\section{Effects of reynolds number on the vertical distributions of algae}

AN Qiang, LONG Tianyu, LIU Chunjing, LEI Yu \& LI Zhe

(Key Laboratory of the Three Gorges Reservoir Region's Eco-environment, Ministry of Education, Chongqing University, Chongqing 400045, P. R. China)

\begin{abstract}
Through a self-designed experimental device according to hydrodynamic conditions of backwater area of branch of Three Gorges Reservoir, the experiment was carried out to study the effects of reynolds number and turbulent flow on the vertical distributions of algae and its suspension and gathered behavior in different water depths. In the condition that water temperature is $20^{\circ} \mathrm{C}$, illumination is $5000 \mathrm{~lx}$ and there are enough nutrient concentrations in water, the experiment results showed that Cyanophyta cells are mainly in the depth ranging from $0.2 \mathrm{~m}$ to $0.8 \mathrm{~m}$ when average flow velocity is within $0-0.005 \mathrm{~m} / \mathrm{s}$ and reynolds number is within $0-1750$ while Bacillariophyta cells are mainly in the depth ranging from $0.2 \mathrm{~m}$ to $0.8 \mathrm{~m}$ when average flow velocity is within $0.1-0.5 \mathrm{~m} / \mathrm{s}$ and reynolds number is within $35000-175000$. Compared to Cyanophyta and Bacillariophyta, a considerable part of Chlorophyta cells could suspend in the depth ranging from $0.2 \mathrm{~m}$ to $0.8 \mathrm{~m}$ when flow velocity is within $0-0.05 \mathrm{~m} / \mathrm{s}$ and reynolds number is within $0-17500$.
\end{abstract}

Keywords: Reynolds number; turbulent flow; algae; vertical distribution; Three Gorges Reservoir

水体中浮游藻类的数量变化和种群演替, 除了受营养盐、温度、光照及自身生理生态状态等的影响外, 还和水体的水动力条件有关 ${ }^{[1-3]}$. 三峡水库蓄水后, 水体的水动力条件发生了很大的变化, 导致次级河流回 水段藻类异常繁殖的水华现象不断,给库区的生态和谐与水环境安全带来了严重影响 ${ }^{[4-6]}$. 水库蓄水后的次 级河流回水段,即使在流速很低的蓄水期,由于其水力半径较大, 流动仍处于紊流状态. 流速和紊流脉动强 度都是表征水动力特性的重要参数.

Hondzo 等 ${ }^{[7-8]}$ 分别采用模拟科特流的旋转同轴圆柱体和垂直方向的振动格栅研究了紊流对四角栅藻和 四尾栅藻生长的影响,研究结果显示:栅藻的生长随着紊流强度的增加而逐渐受到抑制; 在紊流水体中能观

* 国家水体污染控制与治理科技重大专项项目(2009ZX07104-002)、国家自然科学基金项目(51009155)和重庆市自 然科学基金项目 (CSTC,2011 BB7085) 联合资助. 2011-10-10 收稿;2012-02-21 收修改稿. 安强,男,1979 年生, 讲师;E-mail : anqiang@cqu.edu.cn.

** 通信作者;E-mail:longty128@ cqu. edu.cn. 
察到藻类细胞破坏、死亡或活细胞的聚集等现象; 一定强度的紊流作用下, 四尾栅藻更易发生聚集. Hondzo 等在对实验室研究和现场测试结果分析研究的基础上,认为在紊流水体中,与紊流脉动产生的能量耗散率 对应的柯尔莫戈罗夫 (Kolmogorov) 速度是影响藻类生长和对营养盐吸收的重要参数. 此外, 紊流产生的紊流 脉动也会对藻类所受的浮力产生影响, 从而影响藻类的生长与聚集 ${ }^{[9-10]}$.

迄今为止, 国内外对紊流以及紊流脉动对藻类生长和种类演替等作用的研究甚少, 且相关研究主要针 对紊流对藻类的生理指标的影响, 如对生长率、营养吸收率或捕食率的影响等, 研究通常取水面下某深度处 的参数值作为代表, 而对于雷诺数对藻类垂向分布特性的影响以及雷诺数对不同水深处藻类的悬浮和聚集 行为的作用等研究鲜见报道.

雷诺数表征流体所受惯性力与黏性力的对比关系 ${ }^{[1]}$. 当流动的雷诺数小于临界雷诺数时, 流动受黏性 作用控制, 黏性使因微小扰动所引起的紊动衰减, 流动为层流; 随着雷诺数的增大, 黏性作用减弱, 惯性对紊 动的激励作用增强, 流动受惯性力的控制而转变为紊流. 三峡水库次级河流回水区的流场为紊流流场, 惯性 力主导下的紊流脉动是紊流的基本特性. 考虑到在实际河流中, 影响藻类垂向分布和聚集行为的因素除水 动力条件外, 其它因素如光照、水温、营养盐等也会影响藻类垂向分布和聚集, 因此, 针对紊流以及紊流脉动 对藻类的作用,本研究通过自行设计的实验装置,在保持水体中其它环境条件不变的情况下,依据次级河流 回水区的雷诺数范围, 研究雷诺数对藻类垂向分布以及对不同水深处藻类的悬浮和聚集行为的影响, 旨在 探讨紊流对藻类生长和种群演替的影响机理, 为富营养化的防治提供一定的理论依据.

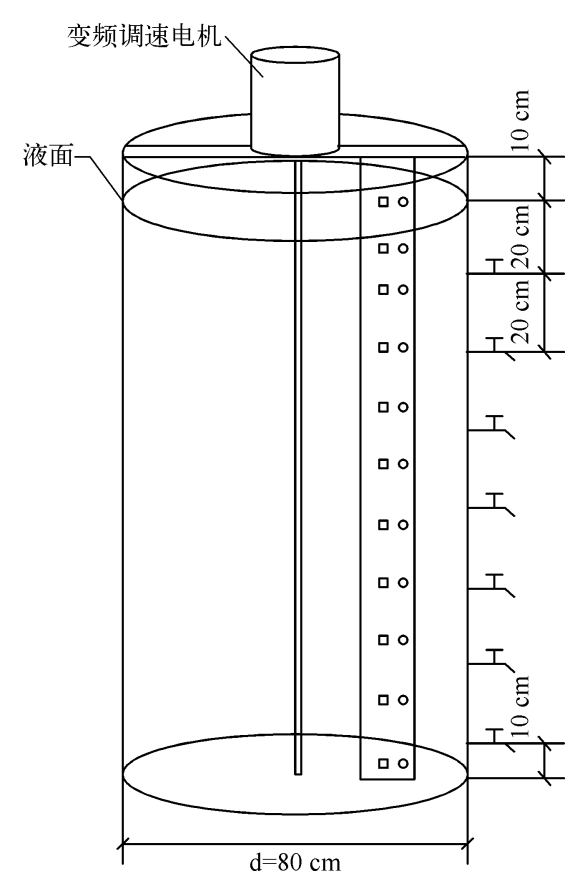

图 1 实验装置示意图

\section{1 材料与方法}

\section{1 实验仪器及装置}

实验装置为自行设计的环形水槽水流装置 (图 1), 装置 材料为不透光材料, 内环半径为 $0.2 \mathrm{~m}$ 、外环半径为 $0.8 \mathrm{~m}$ 、高 为 $1.6 \mathrm{~m}$. 水槽中心放置 $100 \mathrm{YYJ}-180$ 东洋齿轮无级调速电 机, 水在环形水槽中沿周向运动. 考虑到紊流时真光层中水 体的纵向流速在垂向上十分均匀, 为使实验流场尽可能地接 近三峡水库典型次级河流回水段真光层中的实际情况 ${ }^{[11]}$, 让 电机带动桨板推动水流运动, 这可使水流沿周向运动的速度 沿垂向均匀,通过计算,浆片宽度定为 $0.2 \mathrm{~m}$, 浆片位于过流 断面的中部, 并在其上均匀开两排小孔, 间距为 $5 \mathrm{~cm}$, 以减少 因浆片运动在浆片表面引起的水流紊乱. 水槽壁上设 7 个取 样点, 间距为 $0.2 \mathrm{~m}$, 最低的取样点距底部 $0.1 \mathrm{~m}$. 实验过程中 用 LS45A 型旋杯式流速仪测定流速,通过改变变频电机的转 速来改变流速.

\section{2 实验设计与方法}

取嘉陵江磁器口段原水作为实验用水. 原水中的营养盐 水平较高, 总氮浓度为 $2.0 \sim 2.2 \mathrm{mg} / \mathrm{L}$ 、总磷浓度为 $0.19 \sim$ $0.21 \mathrm{mg} / \mathrm{L}$, 处于富营养状况, 因此在适宜的环境条件下,水动 力条件是水华暴发的关键因素. 实验期间所用原水的总氮和 总磷浓度、 $\mathrm{pH}$ 值和溶解氧浓度变化较小. 原水中主要藻类为

蓝藻、绿藻和硅藻, 鉴于水华优势藻均分布在水体的真光层中, 为研究雷诺数对真光层中藻类垂向分布的影 响, 参考有关文献 ${ }^{[12-13]}$, 实验装置水深设为 $1.5 \mathrm{~m}$. 实验水体的光照和水温条件依据三峡水库水华高发时段 的气候状况设置, 水温设为 $20^{\circ} \mathrm{C}$; 光照强度设为 $5000 \mathrm{~lx}$. 实验中, 水温由 HS-300 防暴型加热棒控制, 精确度 $\pm 1^{\circ} \mathrm{C}$; 光照强度用节能日光灯提供光源, 用 ZDS-10 型照度计测定其强度; 光暗比用继电器自动控制, 时间 比为 $12 \mathrm{~h} \mathrm{:} 12 \mathrm{~h}$; 根据水库次级河流回水段的雷诺数范围, 实验的雷诺数 $\left(R e=V d_{\mathrm{e}} / v\right.$, 式中, $V$ 为水流的断面 平均流速; $d_{\mathrm{e}}$ 为过流断面的当量直径; $v$ 为水的运动黏度 $)^{[11]}$ 分别为 $0 、 1750 、 17500 、 35000$ 和 175000 , 对应的 
断面平均流速分别为 $0 、 0.005 、 0.05 、 0.1$ 和 $0.5 \mathrm{~m} / \mathrm{s}$, 实验在五套装置中同时进行. 实验开始时摚拌水体, 让 藻类沿垂向均匀分布, 在实验开始后的第 $5 \mathrm{~d} 10$ :00 采样,每组实验重复两次, 取平均值为实验结果. 水质指 标的测定方法参考《水和废水监测分析方法》(第 4 版) 进行, 藻类细胞密度采用镜检法检测.

\section{2 结果与讨论}

在紊流水体中, 藻类除了受到重力和浮力外, 还会受到紊流脉动引起的雷诺应力的作用. 在河流以及实 验装置中, 藻细胞沿垂向方向的力平衡方程为 ${ }^{[14]}$ :

$$
-\frac{\partial}{\partial z}\left\{m_{\mathrm{p}} \bar{n}_{\mathrm{p}} \overline{W_{\mathrm{p}}^{2}}\right\}-\alpha_{\mathrm{p}} \frac{\partial p}{\partial z}-\alpha_{\mathrm{p}} \rho_{\mathrm{p}} g+\alpha_{\mathrm{p}} \rho_{\mathrm{p}} a+F_{\mathrm{p}, \mathrm{z}}=0
$$

式中, $m_{\mathrm{p}}$ 为藻细胞的质量, $\bar{n}_{\mathrm{p}}$ 为藻细胞的数密度平均值, $\alpha_{\mathrm{p}}$ 为藻细胞所占的体积分数, $\rho_{\mathrm{p}}$ 为藻细胞的密度, $a$ 为藻细胞垂向运动的加速度, $F_{\mathrm{p}, \mathrm{z}}$ 为水体作用于藻细胞垂向上的阻力, $\overline{W_{\mathrm{p}}^{2}}$ 是藻细胞无规则运动 (主要为紊流 脉动) 的垂向分速度的平方平均. 蓝藻、绿藻和硅藻由于细胞结构和形态上的不同, 它们在水体中悬浮的位 置也不同. 从上式可知,在紊流中,由于沿垂向各点的紊流脉动强度不同,紊流脉动作用在藻细胞上的力因 其在垂向的位置不同而不同, 紊流脉动进一步加大了藻类垂向分布的不均匀性, 因此, 紊流和紊流脉动必将 对藻类的空间分布特性产生影响, 从而影响藻类的生长与聚集.

原水中主要藻类为蓝藻、绿藻和硅藻, 考虑到每次实验开始时主要藻类的细胞密度有所不同, 为便于对 比, 采用相对藻密度 (实际密度与沿水深方向最大密度的比) 来分析雷诺数对真光层中藻类垂向分布的 影响.

\section{1 不同雷诺数下蓝藻密度的垂向分布}

在实验的光照强度、水温条件和营养盐水平下, 雷诺数为 0 时, 最大蓝藻密度在水面附近, 随着雷诺数 的增加, 最大蓝藻密度向水深方向移动. 当雷诺数在 $0 \sim 17500$ 范围时, 相对密度大于 0.8 的蓝藻主要聚集在 水深 $0 \sim 0.8 \mathrm{~m}$ 范围内; 当雷诺数为 17500 时, 最大蓝藻密度下移到水深约 $0.6 \mathrm{~m}$ 处, 在水深 $0.2 \sim 0.6 \mathrm{~m}$ 中 的蓝藻也比雷诺数为 0 和 1750 时减少; 当雷诺数增加到 35000 ,蓝藻明显下沉 (图 2a).

从细胞结构上来看,多种蓝藻细胞体内存在具有悬浮性的气囊状伪空胞结构,通过自身调节气囊尺度 和数量改变藻细胞浮力大小来控制它们在水体中的垂向分布、昼夜迁移 ${ }^{[15-16]}$. 在三峡水库的蓄水期,大部分 次级河流回水区流场的雷诺数处在 $0 \sim 17500$ 范围内, 从实验结果分析, 蓝藻自身的浮力调节作用不会受水 流的影响, 而且紊流脉动可以加强蓝藻细胞周围营养盐的交换与运输, 促进蓝藻对营养盐的吸收. 在三峡水 库的泄水期, 大部分次级河流回水区流场的雷诺数大于 35000 , 很可能是因为在高雷诺数流场中, 紊流脉动 产生的雷诺应力过大, 致使大部分蓝藻气囊破裂,浮力下降,蓝藻向水深处迁移.

\section{2 不同雷诺数下绿藻密度的垂向分布}

在实验的光照强度、水温条件和营养盐水平下,随着雷诺数的增加, 最大绿藻密度向水深方向移动, 但 下移的速度小于蓝藻 (图 2b). 各个雷诺数下相对藻密度大于 0.8 的绿藻主要集中在水深 $0.4 \sim 1.2 \mathrm{~m}$ 范围 内, 且在 $0.6 \sim 1.0 \mathrm{~m}$ 水深附近绿藻密度比较稳定, 受雷诺数变化影响较小, 分布相对均匀. 在 $0 \sim 175000$ 雷 诺数范围内,随着雷诺数的增加, $0.8 \mathrm{~m}$ 水深以下呈现绿藻整体下移趋势, $1.0 \mathrm{~m}$ 水深以上呈现整体上移趋 势. 结果表明,在三峡水库的蓄水期和泄水期的水动力条件下,大部分次级河流回水区流场的雷诺数对绿藻 生长的影响较小.

从细胞结构上来看,绿藻细胞形态多样,有单细胞、群体、丝状分枝或不分枝等,具备多种形态的绿藻细 胞在各个流速水体中均能适应相应流场的形态类型成为优势藻 ${ }^{[15-16]}$; 相对于蓝藻细胞, 具有鞭毛结构的绿 藻细胞有着更大的移动自由度、移动方向的选择性和灵活性,而且调节更加直接快速, 因此当水体的水动力 条件发生变化时, 绿藻能很快适应各种雷诺数下的水体, 选择在适合其生长的水层悬浮聚集.

\section{3 不同雷诺数下硅藻密度的垂向分布}

在实验的光照强度、水温条件和营养盐水平下, 在 $0 \sim 1750$ 的雷诺数范围内, 硅藻处于下沉状态, 当雷 诺数增至 $17500 \sim 175000$ 的范围时, 硅藻细胞密度的峰值明显上升至水深 $0.4 \sim 0.8 \mathrm{~m}$ 处, 相对密度大于 0.8 


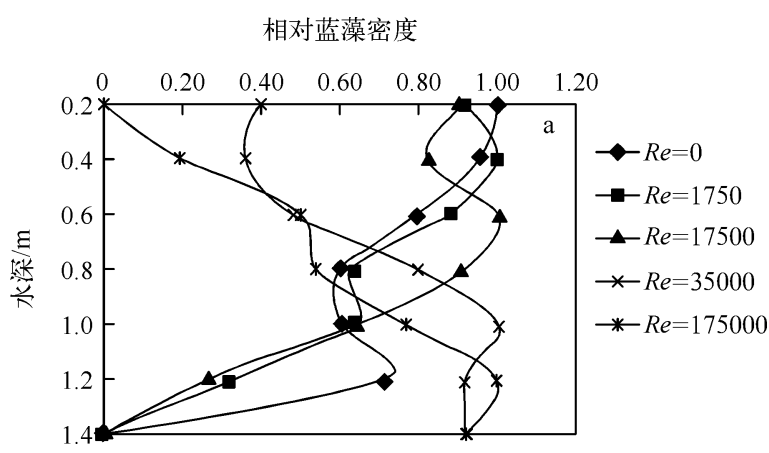

相对绿藻密度

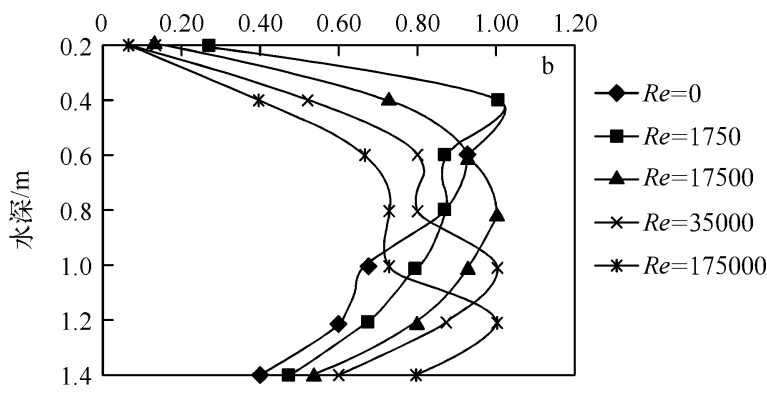

相对硅藻密度

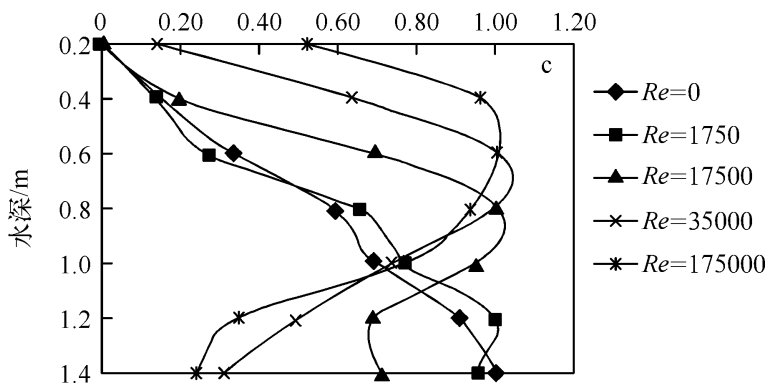

图 2 沿水深方向的蓝藻、绿藻和硅藻密度分布

Fig. 2 Vertical distribution of Cyanophyta,

Chlorophyta and Bacillariophyta densities
的硅藻主要聚集在水深 $0 \sim 1 \mathrm{~m}$ 范围内, 紊流 脉动对硅藻的上浮起促进作用 (图 2c). 结果 表明,在三峡水库的泄水期大部分次级河流处 于高雷诺数紊流状态, 较适宜硅藻生长.

由于硅藻细胞具有高度硅质化的细胞壁 结构, 细胞比重大, 下沉速度较大, 并且既不 具备气囊或鞭毛等细胞结构, 也不具备自身 的浮力调节能力, 因此, 硅藻细胞的在水体中 的悬浮机制与水中泥沙类似, 需要借助流动 水体产生的浮力而上浮 ${ }^{[17]}$. 因此在流场雷诺 数较小, 紊流脉动产生的雷诺应力不足以令 硅藻细胞上浮的浮力时, 硅藻细胞处于持续 下沉状态; 当雷诺数逐渐增大, 雷诺应力也随 之变大, 硅藻细胞所受的上浮力增加, 出现上 移的趋势.

\section{4 不同雷诺数下藻密度垂向分布对比}

水深为 $0.2 \sim 0.8 \mathrm{~m}$ 的表层水体光照充 足, 在此水深范围内悬浮聚集的藻类相对悬浮 于其他水深的藻类更有可能成为水华优势藻. 在实验的光照强度、水温条件和营养盐水平 下, 当雷诺数在 $0 \sim 1750$ 时, 在距水面 $0.2 \sim$ $0.4 \mathrm{~m}$ 的表层水体中, 硅藻的密度几乎为零; 而雷诺数增至 175000 时, 蓝、绿藻的密度在 $0.2 \mathrm{~m}$ 水深以内几乎为零. 当雷诺数在 $0 \sim$ 1750 时, 蓝藻主要悬浮聚集在 $0.2 \sim 0.8 \mathrm{~m}$ 的 表层水体中, 而硅藻处于下沉状态. 当雷诺数 在 $35000 \sim 175000$ 时, 硅藻主要悬浮聚集在 $0.2 \sim 0.8 \mathrm{~m}$ 的表层水体中, 而蓝藻处于下沉状 态. 与蓝藻和硅藻相比, 绿藻适宜的雷诺数范 围更宽,当雷诺数在 $0 \sim 17500$ 时,绝大部分绿 藻都能悬浮聚集在 $0.2 \sim 0.8 \mathrm{~m}$ 的表层水体中 ( 图 3 ).

\section{3 结论}

针对三峡水库次级河流回水区水华高发时段的气候条件和营养盐水平,依据三峡水库次级河流回水段 的水动力状况, 自行设计了水流实验装置, 研究不同雷诺数下主要藻类的垂向分布特性以及雷诺数对不同 水深处主要藻类的悬浮和聚集行为的影响, 研究表明:

1) 在水温为 $20^{\circ} \mathrm{C}$ 、光照强度为 $5000 \mathrm{~lx}$ 的富营养水体中, 当雷诺数在 $0 \sim 1750$ 范围、流场流速在 $0 \sim$ $0.005 \mathrm{~m} / \mathrm{s}$ 时, 蓝藻主要悬浮聚集在 $0.2 \sim 0.8 \mathrm{~m}$ 的表层水体中, 有利于蓝藻的生长, 而硅藻处于下沉状态;

2 ) 在水温为 $20^{\circ} \mathrm{C}$ 、光照强度为 $5000 \mathrm{~lx}$ 的富营养水体中, 当雷诺数在 $35000 \sim 175000$ 范围、流场流速在 $0.1 \sim 0.5 \mathrm{~m} / \mathrm{s}$ 时, 硅藻主要悬浮聚集在 $0.2 \sim 0.8 \mathrm{~m}$ 的表层水体中,而蓝藻处于下沉状态;

3 ) 在水温为 $20^{\circ} \mathrm{C}$ 、光照强度为 $5000 \mathrm{~lx}$ 的富营养水体中, 与蓝藻和硅藻相比, 绿藻适宜的雷诺数范围更 宽, 当雷诺数在 $0 \sim 17500$ 范围、流场流速在 $0 \sim 0.05 \mathrm{~m} / \mathrm{s}$ 时, 绝大部分绿藻都能悬浮聚集在 $0.2 \sim 0.8 \mathrm{~m}$ 的 表层水体中. 
相对藻密度

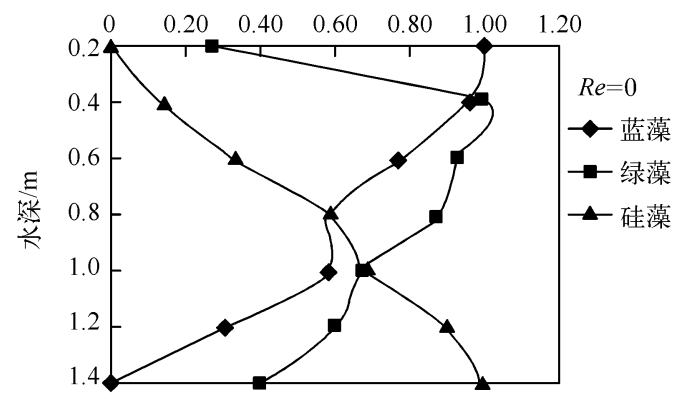

相对藻密度

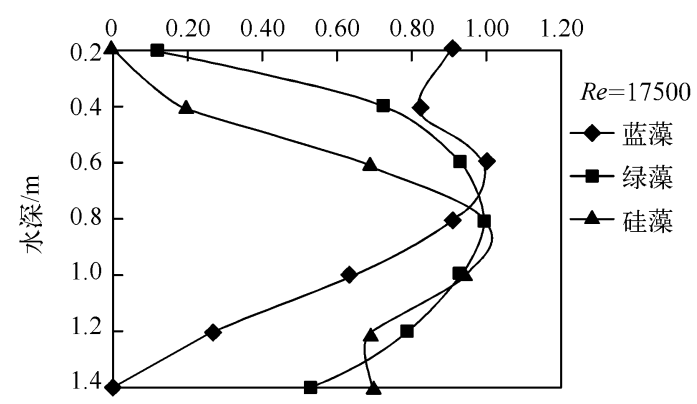

相对藻密度

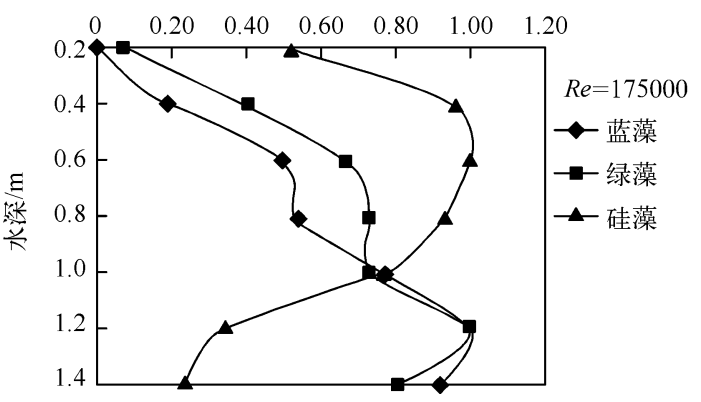

相对藻密度

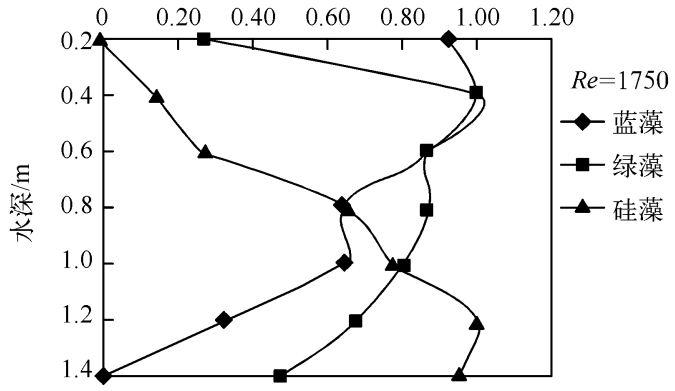

相对藻密度

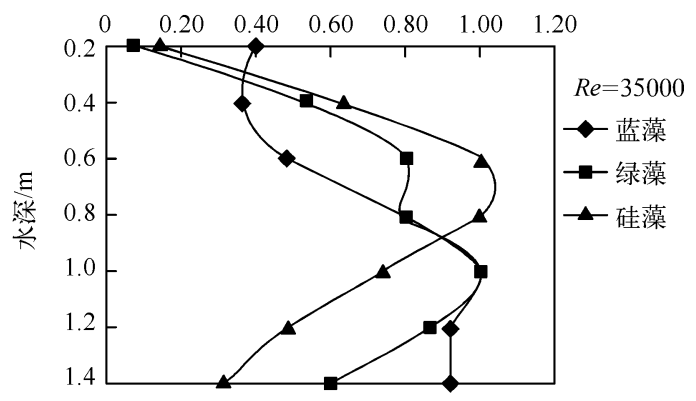

图 3 不同雷诺数下藻类密度分布

Fig. 3 Distribution of algae densities at five reynolds numbers

\section{4 参考文献}

[ 1 ] Steinman AD, Mcintire CD. Effects of current velocity and light energy on the structure of periphyton assemblages in laboratory streams. Journal of Phycology, 1986, 22 : 352-361.

[ 2 ] Borchardt MA. Effects of flowing water on nitrogen and phosphorus-limited photosynthesis and optimum N:P ratios by Spirogyra fluviatilis( Charophyceae). Journal of Phycology, 1994, 30 : 418-430.

[ 3 ] Escart HJ, Aubrey DG. Flow structure and dispersion within algal mats. estuarin. Coastal and Shelf Science, 1995, 40 : $451-472$.

[ 4 ] 张 远, 郑丙辉, 刘鸿亮. 三峡水库蓄水后的浮游植物特征变化及影响因素. 长江流域资源与环境, 2006, 15 (3) :254-258.

[5] 代玲玲. 三峡水库富营养化藻类特征及环境因素影响研究 [学位论文]. 重庆: 重庆大学, 2007: 11-12. 
[6]周贤杰, 罗固源, 杨清玲等. 三峡库区次级河流回水区环境因子对藻类生长影响的模拟实验研究. 环境科学学报, $2008,28(3): 558-562$.

[ 7 ] Hondzo M, Al-Homoud A. Model development and verification for mass transport to Escherichia coli cells in a turbulent flow. Water Resources Research, 2007, 43(8): W08413. 1-W08413. 11.

[ 8 ] Hondzo M, Warnaars TA. Coupled effects of small-scale turbulence and phytoplankton biomass in a small stratified lake. Journal of Environment Engineering, 2008, 134(12) : 954-960.

[ 9 ] Poff NL, Wellnitz T, Monroe J. Redundancy among stream grazers across a current velocity gradient. Oecologia, 2003, 134: 262-269.

[10] 王 华, 逢 勇. 藻类生长的水动力因素与数值仿真. 环境科学, 2008, 29(4) : 884-889.

[11］龙天渝,蔡增基. 流体力学. 北京:中国建筑工业出版社, 2004: 99-102.

[12] Hu W, Gladue R, Hansen J et al. Growth inhibition of dinoflagellate algae in shake flasks: not due to shear this time! Biotechnol Progress, 2010, 26(1) : 79-87.

[13] Lmer J, Francesc P, Celia M. Experimental analysis of coagulation of particles under low-shear flow. Water Research, 2005, 39: 2994-3000.

[14] 刘大有. 关于颗粒悬浮机理和悬浮功的讨论. 力学学报, 1999, 31(6): 661-670.

[15] 刘信安, 张密芳. 重庆主城区三峡水域优势藻类的演替及其增殖行为研究. 环境科学, 2008, 29(7): 1839-1843.

[16] 曾 辉. 长江和三峡库区浮游植物季节变动及其与营养盐和水文条件关系研究 [学文论文]. 北京: 中国科学院研 究生院, 2006 : 95-104.

[17] 龙天渝, 周鹏瑞, 吴 否. 环境因子对香溪河春季藻类生长影响的模拟实验. 中国环境科学, 2011, 31 (2) : 327-331. 